DOI :

\title{
Current Status of Clostridium Difficile Infection in Humans
}

\author{
Mahendra Pal*, Mati Roba Bulcha** and Wakuma Mitiku Bune*** \\ *Narayan Consultancy on Veterinary Public Health and Microbiology- Anand-388001, Gujarat, India **Yemalog \\ Walal Woreda Livestock and Fishery Development and Resource Office, Kellem Wollega Zone, Oromia, Ethiopia. \\ **: Ambo University, Guder Mamo Mezemer Campus, Veterinary Laboratory Technology, Ambo, Ethiopia \\ *Corresponding Author: Prof.Dr.Mahendra Pal, Founder Director of Narayan Consultancy on Veterinary Public \\ Health and Microbiology, Aangan, Jagnath Ganesh Dairy Road, Anand-388001, Gujarat, India. E-mail: \\ palmahendra2@gmail.com
}

\begin{abstract}
Community acquired Clostridium difficile infection is recognized as an increasing public health threat. In developed countries, Clostridium difficile, an anaerobic spore-forming gram-positive bacterium, is the most important cause of healthcare associated diarrhea. The health effects of $C$. difficile infections in a human were not recognized until the 1970s. Antibiotic treatments allow Clostridium difficile to germinate sufficiently to establish infection. Because of the emergence of a more virulent strain, the incidence and severity of Clostridium difficile infection (CDI) have increased dramatically in high-income countries. The spores of Clostridium difficile are resistant to commonly used decontaminants and can persist for long periods without the loss of viability. The diagnosis of Clostridium difficile infection poses a challenge to health professionals. The use of clindamycin and penicillin's has been traditionally considered to cause the greatest risk of infection. Oral therapy with vancomycin and fidaxomicin are the considered the mainstay of CDI treatment. Application of proper hand hygiene before and after contact of a patient with CDI is a simple practical step to minimize the infection.
\end{abstract}

KE YW O DS : Anaerobic bacterium, Clostridium difficile, Community acquired infection, Hand hygiene, Diarrhea, Public health threat, Spores

\section{Introduction}

In developed countries, Clostridium difficile is the most important cause of healthcare-associated diarrhea (Jury et al., 2013). Clostridium difficile (C. difficile) is a major public health problem that directly affects patient safety and causing significant health and economic consequences to the healthcare system (De Roo and Regenbogen, 2020).

Clostridium difficile is an anaerobic spore-forming gram-positive bacillus, which acquired from the environment or by the fecal-oral route, and it is a major cause of antibiotic-associated diarrhea and colitis in the industrialized world (Vely and Ferrada, 2020; Pal and Bulcha, 2021). The health effects of C.difficile infections in a human were not recognized until the 1970s. Different studies demonstrated that $C$. difficile-associated disease (CDAD) encompasses a range of disease severity from toxic megacolon, which can result in even death.

The source of acquisition of $C$. difficile in community-associated cases is unclear (Jury et al., 2013). Because of the emergence of a more virulent strain, the incidence and severity of CDI have increased dramatically in high-income countries (Gingras et al., 2016). The spores of this anaerobic bacterium are resistant to commonly used decontaminants and can persist for long periods without the loss of viability.
Antibiotic treatments allow $C$. difficile to germinate sufficiently to establish infection. The formation of vegetative cells through the germination of spores followed by attachment to intestinal epithelial cells is a critical step in the pathogenesis. Therapy with clindamycin and penicillin has been attributed to cause the most risk of the infection to the patient. For the development of $\mathrm{C}$. difficile disease, antibiotics are the major risk factor because of the loss of endogenous microbiota that allows $C$. difficile to proliferate and invade. Preventing ingestion of the organism and its spores by patients are control measures for C. difficile (Vely and Ferrada, 2020). The present communication delineates the current status of Clostridium difficile infection in humans.

\subsection{Source and transmission}

The potential sources of $\mathrm{C}$. difficile in the community are not fully understood (Chitnis et al., 2013). Clostridium difficile is a major risk in healthcare settings and causes increasing prevalence in the broader community (Durham et al., 2016). The organism is ingested either as the vegetative form or as spore form. Patients shed spores into the environment (Gupta and Khanna, 2014).

Horizontal transmission from symptomatic patients continues to be viewed as the source of most cases of infection (Surawicz et al., 2013). In the environment, $C$. difficile may be ubiquitous. C. difficile is found in most mammals, and various birds and reptiles' intestinal tract. 
Patients with asymptomatic colonization and sources in the wider environment, such as water, farm animals, and food products such as processed meat, fish, and vegetables can also contain C. difficile (Hensgens et al., 2012; Pal and Bulcha,2021). Whole-genome sequencing is helping to track transmission across health-care facilities, countries, and continents (Martin et al., 2016).

\subsection{Pathogenesis and Clinical Features}

After a personal contact with the spores of a toxin-producing strain of C. difficile, spores colonize the large intestine and results in alteration of the normal colonic microbiota, permitting colonization of the organism (Britton and Young, 2012), and C. difficile starts to dominate large intestine, which might be the first step of infection. Clostridium difficile virulence is mostly due to enzymes and toxins leading to disruption of fluid secretion, neutrophil adhesion, and local inflammation. Toxins produced by C. difficile are transported to the cell cytoplasm, where they inactivate the Rho family of GT Pases result in the inflammatory process intensifies. The Rho protein takes part in actin polymerization, and result in stabilizes the cell cytoskeleton. Micro ulcerations covered with pseudomembranes start to occur on the intestinal mucosal surface (Loo et al., 2011). In severe cases, it causes diarrhea, abdominal pain, fever, nausea, vomiting, leukocytosis, raised C-reactive protein, and low albumin level (Monaghan et al., 2015; Pal and Bulcha, 2021).

\subsection{Diagnosis and Treatment}

The diagnosis of C. difficile associated diarrhea requires a careful history of the patient. A detailed description of the patient's diarrhea is important in differentiating other causes of diarrhea (Loo et al., 2011).History of fever, immunosuppression, previous infection with $\mathrm{C}$. difficile, recent change in bowel habits, and the presence of abdominal symptoms are considered. An enzyme immunoassay that detects toxins $\mathrm{A}$ and $\mathrm{B}$ is the most common for diagnosing the infection (Simor, 2010). Glutamate dehydrogenase (GDH) tests based are characterized by rapid turnaround time as well as a specificity of almost 100\% (Czepiel et al., 2019). Currently, the American Society of Colon and Rectal Surgeons (ASCRS) recommended a combined bowel preparation (CBP) that involves both mechanical (MBP) and oral antibiotic (ABP) components (Mangieri et al., 2021).

According to IDSA guidelines published in February 2018, the treatment of choice for CDIs is oral vancomycin or fidaxomicin, with oral metronidazole (Vely and Ferrada, 2020). Rifaximin, tigecycline, and bacitracin other treatment regimens but the pieces of data supporting their efficacy are inadequate (Kechagias et al., 2020).
Presently, vancomycin and fidaxomicin are the considered the cornerstones of CDI treatment (Czepiel et al., 2019). Lantibiotics are antimicrobial peptides that exhibit potent activity against $\mathrm{C}$. difficile. Lantibiotics possess novel modes of action with lower rates of resistance development and less deleterious effect on the protective gut microbiota (Sandiford, 2019).

\subsection{Prevention and Control}

The primary means of transmission are from environment-to-person or person-to-person via the fecal-oral route (Bloomfield and Riley 2016). If there is direct contact with feces, hand washing with soap and water is imperative. To decrease transmission to other patients, it is essential to accommodate patients with CDI in a private room with a dedicated toilet. Good hand hygiene before and after contact of a patient with CDI is very mandatory. It is advised that antibiotics to be prescribed to the patient for treatment should be based on the local epidemiology and C. difficile strains (Jakobsson et al., 2010).

\section{Conclusion and Recommendations}

Clostridium difficile infection is potentially life-threatening, especially in elderly people and in patients in hospitals and communities worldwide. Now it has emerged in the community in populations previously considered low risk. Close contacts, the environment, animals, and food are potential sources of this infection. The diagnosis of $\mathrm{C}$. difficile infection continues to be a challenge for health workers. Further surveillance methods are needed to monitor the incidence and to identify a way of transmission. Based on the above conclusion, the following recommendations are forwarded:

- All hospital staff should wear gloves and gowns to minimize contamination when entering rooms with CDI patients and when caring for them.

- Proper washing of hands with soap and water before and after contact with CDI patients is advised.

- It is emphasized to minimize the frequency and duration of high-risk antibiotic therapy.

- Further research on the pathogenesis, and epidemiology should be conducted.

\section{Acknowledgment}

The authors are very thankful to Prof.Dr.R.K.Narayan for his suggestions during the preparation of manuscript and Anubha Priyabandhu for computer help. 


\section{Contribution of Authors}

All the authors contributed equally. They read the final version, and approved it for publication.

\section{Conflict of interest}

The authors declare that they do not have conflict of interest.

\section{Source of Financial Grant}

There was no financial support for this manuscript.

\section{References}

1. Bloomfield LE and Riley TV (2016). Epidemiology and risk factors for community-associated Clostridium difficile infection: a narrative review. Infectious diseases and therapy, 5(3):231-251.

2. Britton RA and Young VB (2012). Interaction between the intestinal microbiota and host in Clostridium difficile colonization resistance. Trends in microbiology, 20(7):313-319.

3. Chitnis AS, Holzbauer SM, Belflower RM, Winston LG, Bamberg WM, Lyons C, Farley MM, Dumyati GK, Wilson LE, Beldavs ZG and Dunn JR (2013). Epidemiology of community-associated Clostridium difficile infection, 2009 through 2011. JAMA Internal Medicine, 173(14):1359-1367.

4. Czepiel J, Dróżdż M, Pituch H, Kuijper EJ, Perucki W, Mielimonka A, Goldman S, Wultańska D, Garlicki A and Biesiada G (2019).

5. Clostridium difficile infection. European Journal of Clinical Microbiology and Infectious Diseases, 38(7):1211-1221.

6. De Roo AC and Regenbogen SE (2020). Clostridium difficile Infection: An Epidemiology update. Clinics in colon and rectal surgery, 33(2):49.

7. Durham DP, Olsen MA, Dubberke ER, Galvani AP and Townsend JP (2016). Quantifying transmission of Clostridium difficile within and outside healthcare settings. Emerging infectious diseases, 22(4):608.

8. Gingras G, Guertin MH, Laprise JF, Drolet M and Brisson M (2016). Mathematical modeling of the transmission dynamics of Clostridium difficile infection and colonization in healthcare settings: a systematic review. Plos One, 11(9): E0163880.

9. Gupta A and Khanna S (2014). Community-acquired Clostridium difficile infection: an increasing public health threat Infection and drug resistance, 7:63.
10. Hensgens MP, Keessen EC, Squire MM, Riley TV, Koene MG, de Boer E, Lipman LJ and Kuijper EJ (2012). Clostridium difficile infection in the community: a zoonotic disease?. Clinical Microbiology and Infection, 18(7):635-645.

11. Jakobsson HE, Jernberg C, Andersson AF, Sjolund-Karlsson M, JanssonJK and Engstrand L (2010). Short-term antibiotic treatment has differing long-term impacts on the human throat and gut microbiome. PLoS One, 5(3): E9836.

12. Jury LA, Sitzlar B, Kundrapu S, Cadnum JL, Summers KM, Muganda CP, Deshpande A, Sethi AK and Donskey CJ (2013). Outpatient healthcare settings and transmission of Clostridium difficile. PLoS One, 8(7):E70175.

13. Kechagias KS, Chorepsima S, Triarides NA and Falagas ME (2020). Tigecycline for the treatment of patients with Clostridium difficile infection: an update of the clinical evidence. European Journal of Clinical Microbiology and Infectious Diseases, 39(6):1053-1058.

14. Loo VG, Bourgault AM, Poirier L, Lamothe F, Michaud S, Turgeon N, Toye B, Beaudoin A, Frost EH, Gilca R and Brassard P (2011).

15. Host and pathogen factors for Clostridium difficile infection and colonization. New England Journal of Medicine, 365(18):1693-1703.

16. Mangieri CW, Ling JA, Modlin DM, Rose ED and Burgess PL. Utilization of combination bowel preparation (CBP) is protective against the development of post-operative Clostridium difficile infection (CDI), decreases septic complications, and provides a survival benefit. Surgical Endoscopy, 35(2):928-933.

17. Martin JS, Monaghan TM and Wilcox MH (2016). Clostridium difficile infection: epidemiology, diagnosis and understanding transmission. Nature Reviews Gastroenterology and Hepatology, 13(4):206.

18. Monaghan TM, Cockayne A and Mahida YR (2015). Pathogenesis of Clostridium difficile infection and its potential role in inflammatory bowel disease. Inflammatory bowel diseases, 21(8):1957-1966.

19. Pal M. and Bulcha MR (2021). Clostridium difficile as an emerging foodborne pathogen of public health significance. Acta Scientifc Microbiology 4(5): 46-49.

20. Sandiford SK (2019). Current developments in lantibiotic discovery for treating Clostridium difficile infection. Expert Opinion on Drug Discovery, 14(1):71-79. 
21. Simor AE (2010). Diagnosis, management, and prevention of Clostridium difficile infection in long-term care facilities: A review. Journal of the American Geriatrics Society, 58(8):1556-1564.

22. Surawicz CM, Brandt LJ, Binion DG, Ananthakrishnan AN, Curry SR, Gilligan PH, McFarland LV, Mellow $M$ and Zuckerbraun BS (2013). Guidelines for diagnosis, treatment, and prevention of Clostridium difficile Infections. American Journal of Gastroenterology, 108(4): 478-498.
23. Vely A and Ferrada P (2020). Clostridioides difficile Infection: Role of Surgery in Clostridium difficile Infection. Clinics in colon and rectal surgery, 33(2):87.

Citation: Mahendra Pal*, Mati Roba Bulcha** and Wakuma Mitiku Bune***, "Current Status of Clostridium Difficile Infection in Humans". American Research Journal of Biosciences, Volume 7, Issue No. 1, 2021 , pp. 1-4.

Copyright (C) 2021 Mahendra Pal*, Mati Roba Bulcha** and Wakuma Mitiku Bune***, This is an open access article distributed under the Creative Commons Attribution License, which permits unrestricted use, distribution, and reproduction in any medium, provided the original work is properly cited. 